2000s-18

\title{
Confidence Regions for Calibrated Parameters in Computable General Equilibrium Models
}

Touhami Abdelkhalek, Jean-Marie Dufour

Série Scientifique
Scientific Series

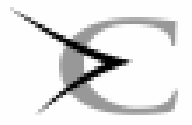




\section{CIRANO}

Le CIRANO est un organisme sans but lucratif constitué en vertu de la Loi des compagnies du Québec. Le financement de son infrastructure et de ses activités de recherche provient des cotisations de ses organisationsmembres, d'une subvention d'infrastructure du ministère de la Recherche, de la Science et de la Technologie, de même que des subventions et mandats obtenus par ses équipes de recherche.

CIRANO is a private non-profit organization incorporated under the Québec Companies Act. Its infrastructure and research activities are funded through fees paid by member organizations, an infrastructure grant from the Ministère de la Recherche, de la Science et de la Technologie, and grants and research mandates obtained by its research teams.

\section{Les organisations-partenaires / The Partner Organizations}

•École des Hautes Études Commerciales

-École Polytechnique

-Université Concordia

-Université de Montréal

-Université du Québec à Montréal

-Université Laval

-Université McGill

-MEQ

-MRST

-Alcan Aluminium Ltée

-Banque Nationale du Canada

-Banque Royale du Canada

-Bell Québec

-Développement des ressources humaines Canada (DRHC)

-Fédération des caisses populaires Desjardins de Montréal et de l'Ouest-du-Québec

-Hydro-Québec

-Imasco

-Industrie Canada

-Raymond Chabot Grant Thornton

- Téléglobe Canada

-Ville de Montréal

(C) 2000 Touhami Abdelkhalek et Jean-Marie Dufour. Tous droits réservés. All rights reserved. Reproduction partielle permise avec citation du document source, incluant la notice $@$.

Short sections may be quoted without explicit permission, provided that full credit, including (C) notice, is given to the source.

Ce document est publié dans l'intention de rendre accessibles les résultats préliminaires de la recherche effectuée au CIRANO, afin de susciter des échanges et des suggestions. Les idées et les opinions émises sont sous l'unique responsabilité des auteurs, et ne représentent pas nécessairement les positions du CIRANO ou de ses partenaires.

This paper presents preliminary research carried out at CIRANO and aims at encouraging discussion and comment. The observations and viewpoints expressed are the sole responsibility of the authors. They do not necessarily represent positions of CIRANO or its partners. 


\title{
Confidence Regions for Calibrated Parameters in Computable General Equilibrium Models*
}

\author{
Touhami Abdelkhalek ${ }^{\dagger}$, Jean-Marie Dufour
}

\begin{abstract}
Résumé / Abstract
Nous considérons le problème de la prise en compte de l'incertitude sur les paramètres calibrés de modèles calculables d'équilibre général (MCEG) en construisant des régions (ou des intervalles) de confiance pour ces paramètres. Nous étudions en détail deux méthodes qui permettent de ce faire. La première est une extension des travaux de Abdelkhalek et Dufour (1998) et repose sur une technique de projection qui permet de construire des régions de confiance pour les paramètres calibrés à partir de régions de confiance pour les paramètres libres d'un MCEG déterministe. Nous discutons en détail comment cette approche peut être appliquée aux paramètres d'une fonction CES (de type Armington) d'usage fréquent dans les MCEG et nous l'illustrons sur des modèles de l'économie marocaine. La seconde méthode permet de dépasser le cadre déterministe usuel des MCEG en ajoutant des perturbations aléatoires à certaines équations du modèle pour construire des régions de confiance pour les paramètres calibrés en utilisant des techniques de simulation. Cette méthode utilise aussi le concept classique de fonction pivotale d'un paramètre. Nous discutons en détail comment cette méthode peut être appliquée aux paramèrtes calibrés d'une fonction de production de type Cobb-Douglas.
\end{abstract}

We consider the problem of assessing the uncertainty of calibrated parameters in computable general equilibrium (CGE) models through the construction of confidence sets (or intervals) for these parameters. We study two different setups under which this can be done. The first one extends earlier work from Abdelkhalek and Dufour (1998) and is based on a projection technique which allows the construction of confidence sets for calibrated parameters from confidence sets on the free parameters of a (deterministc) CGE model. We discuss in detail how this approach can be applied to CES (Armington-type) function

\footnotetext{
* Corresponding Author: Jean-Marie Dufour, CIRANO, 2020 University Street, 25 ${ }^{\text {th }}$ floor, Montréal, Qc, Canada H3A 2A5 Tel.: (514) 985-4026 Fax: (514) 985-4039 email: dufourj@ cirano.umontreal.ca The authors thank Bryan Campbell, Bernard Decaluwé, René Garcia, André Martens, Nour Meddahi and Randall Wigle for several useful comments. We are also very grateful to Paul Klassen for his translation and edition work. This research was conducted under the auspices of the PARADI program linking two research centers, C.R.D.E. (Université de Montréal) and CREFA (Université Laval), and financed as a Center of Excellence in International Development by the Canadian Agency for International Development. This work was also supported by the Canadian Network of Centres of Excellence [program on Mathematics of Information Technology and Complex Systems (MITACS)], the Canada Council for the Arts (Killam Fellowship), the Social Sciences and Humanities Research Council of Canada, and the Government of Québec (Fonds FCAR).

$\dagger$ INSEA Rabat

* Université de Montréal, CRDE and CIRANO
} 
parameters frequently used in CGE models and illustrate it on models of the Moroccan economy. The second method allows one to extend the usual deterministic specification of CGE models by adding stochastic disturbances to the equations of the model and then to construct corresponding confidence sets for calibrated parameters using simulation techniques. This method uses the classical concept of a pivotal function for a parameter. We discuss in detail how this method can be applied to the calibrated parameters of a Cobb-Douglas production function.

Mots Clés : Modèles calculables d'équilibre général, calibration, région de confiance, intervalle de confiance, projection, analyse de sensibilité, Maroc

Keywords: Computable general equilibrium models, calibration, sensitivity analysis, confidence set, confidence interval, projection, Morocco 


\section{Contents}

1. Introduction 1

2. Theoretical framework 3

3. Projection-based confidence sets 4

4. Calibrated parameters for CES and CET functions 6

5. Application to CGE models of Morocco 9

6. Confidence regions based on equations with disturbances 10

7. Confidence regions from equations with disturbances: general approach 15

8. Conclusion $\quad 19$

$\begin{array}{lr}\text { A. Multiplicative disturbances } & 20\end{array}$

B. GAMS-MINOS program for the applications $\quad 21$

$\begin{array}{ll}\text { References } & 24\end{array}$ 


\section{Introduction}

Computable general equilibrium (CGE) models have come into extensive use for analyzing and simulating the effects of economic policy changes in developing and industrialized countries. Presentations and overviews of this policy analysis tool may be found in Shoven \& Whalley (1984, 1992), Manne (1985), Devarajan, Lewis and Robinson (1986, 1994), Martens (1993), Decaluwé and Martens (1988) as well as Gunning and Keyzer (1995). These models are generally non-stochastic and strongly nonlinear. Results obtained by simulating these models rely on several assumptions, pertaining both to the behavior of agents and to the choice of exogenous variables (the "closure" of the model). The nature and quality of the available data also affects the results, whether base-year data in static models (the reference year in the social-accounting matrix) or the stationary equilibrium in dynamic models. The values assigned to the parameters of the behavioral functions, which underlie the "calibration" of the model, are no less crucial. In fact, since the work of Mansur and Whalley (1984) and even before, CGE model designers have relied on calibration methods. These generally require a good deal less time and effort than econometric estimation. Calibration relies on a largely arbitrary distinction between "free parameters", which can be obtained from external sources or simply assigned on the basis of subjective judgements, and "calibrated parameters" which are derived ("estimated") from the former so as to reproduce the reference data (e.g. the base-year data). In these methods there clearly exists a level of uncertainty attributable to the selection of free parameters for the model, since these contribute to the calibration process.

The issue of the choice of values for the parameters of CGE models often gives rise to a natural scepticism among those who need to build, analyze, or use these models. In general, these values may be econometric estimates drawn from other studies, figures based on international comparisons, or simply arbitrary values imputed with no supporting data. Elasticities available in the literature are often contradictory and inconsistent. Frequently, they are obtained using sectorial classifications different from those of the model, and pertain to other time periods or even countries. The varying degrees of uncertainty affecting these models transfers to the results of the simulations [see Abdelkhalek and Dufour (1998)]. Since CGE models are rarely estimated using econometric methods [except in the notable work of Jorgenson (1984) and his associates], it is difficult to perform tests on the data or build confidence regions for the calibrated parameters and the endogenous variables of the model. Even if the general specification of the model is not questioned, the credibility of the conclusions suffers from the uncertainty associated with the reference-year data and with the choice of parameters. As to this latter source of uncertainty, Mansur and Whalley (1984, p. 100), among others, emphasize the crucial nature of the latter step in the model building process: "The choice of elasticity values critically affects results obtained with these models", and (p. 103) "The set of elasticity values used are critical parameters in determining the general equilibrium impacts of policy changes generated by these models." Shoven and Whalley (1984), in an article summarizing the main studies realized up to 1984, recognize the key role played by the selection of these parameters in determining economic policy simulations as well as the difficulties encountered by researchers during calibration. They indicate that the method generally used is based upon an arbitrary choice of a point estimate around which sensitivity analysis may be performed. In particular, they write: "The procedure generally employed is to choose a central case specification, around 
which sensitivity analysis can be performed" [Shoven and Whalley (1984, pp. 1030-1031)].

Recognizing the seriousness of this problem, a number of authors have proposed an assortment of approaches in order to translate parameter uncertainty into a measure of uncertainty for the results of the simulations; see especially Pagan and Shannon (1985, 1987), Harrison (1986, 1989), Bernheim, Scholz and Shoven (1989), Harrison and Vinod (1992), Wigle (1986, 1991), Harrison, Jones, Kimbell and Wigle (1993), DeVuyst and Preckel (1997) and Dawkins (1997); for a more detailed description of most of these approaches, see Abdelkhalek (1994). These methods are fundamentally descriptive and do not resort to a rigorous statistical framework. More recently, however, we proposed a more systematic approach, permitting the construction of confidence regions for the endogenous variables of CGE models in order to account for free-parameter uncertainty; see Abdelkhalek and Dufour (1998).

Calibration may be viewed as a two-stage estimation procedure by which, starting from the values of the free parameters and the reference-year data, values are assigned to the calibrated parameters. Like free parameters, these may be interesting from an economic perspective. This method, widely used in studies based on CGE models, has the advantage of being much less demanding than traditional econometric methods, both from the perspective of data requirements and numerical procedures. However, this process has received very little attention in the literature on CGE models. The only theoretical work on the numerical specification, and particularly on the calibration of CGE models, appears in Mansur and Whalley (1984). This work was commented and completed by Lau [comment on Mansur and Whalley (1984, pp. 127-135)]. The deterministic nature of these models has rarely been criticized, and consequently the analysis and study of the calibrated parameters has never been on the agenda of this literature.

In this paper we begin by formulating the problem of calibration in CGE models, specifying two forms under which calibrated parameters appear in them (Section 2). In the first form, they are only functions of the reference-period data, while in the second one they also depend on the free parameters of the model. Drawing on the work of Abdelkhalek and Dufour (1998) on endogenous variables in CGE models, we propose two statistical methods to construct confidence regions for this type of parameter. The first (Section 3) is based on the concept of projection. It enables the model builder to account for the uncertainty associated with calibrated parameters by constructing confidence regions for them using those of the free parameters. In Sections 4 and 5, we illustrate this approach for the calibrated parameter of a constant elasticity of substitution (CES) or transformation (CET) functions (the Armington form), frequently used in CGE models. In Sections 6 and 7, we attempt to move beyond the deterministic framework typical of CGE models by allowing stochastic disturbances to appear in some of the equations of the model. We begin by discussing inference on the parameters of Cobb-Douglas type production functions (Section 6), and then present a more general discussion of the calibration of CGE models with equations containing disturbance terms (Section 7). We conclude in Section 8. 


\section{Theoretical framework}

In its most general form, a CGE model may be represented by a function $M$ such that:

$$
Y=M(X, \beta, \gamma)
$$

where $Y$ is an $m$-dimensional vector of endogenous variables, $M$ is a (generally nonlinear) function which may be analytically quite complicated but remains computable, $X$ is a vector of exogenous or economic policy variables, $\beta$ is a $p$-dimensional vector of free parameters belonging to a subset $\Omega$ of $\mathbb{R}^{p}$, and $\gamma$ is a vector with $k$ elements containing the parameters to be calibrated.

From a theoretical viewpoint, $\beta$ and $\gamma$ are not fundamentally different. However, they play very different roles in these models. While the elements of $\beta$ are parameters (e.g., elasticities) of the behavioral equations of the model (utility/demand, production/supply, imports, exports, etc.), those of $\gamma$ are generally scale or share parameters. The calibration procedure thus consists of setting the vector of parameters $\gamma$ to exactly reproduce the data of a reference year, given a point estimate of the free parameters $\beta$ of the model. Thus, it is not surprising that the choice of these parameters has a large influence on the simulation results.

More formally, consider the equation:

$$
Y_{0}=M\left(X_{0}, \beta, \gamma\right)
$$

where $Y_{0}$ and $X_{0}$ are vectors of endogenous and exogenous variables respectively for a given base year. We solve for $\gamma$ (assuming that the solution exists and is unique):

$$
\gamma=H\left(Y_{0}, X_{0}, \beta\right)=h(\beta)
$$

When an estimate $\hat{\beta}$ of $\beta$ is available, the vector $\gamma$ is estimated by replacing $\beta$ with its estimate in equations (2.3) and (2.2). Furthermore, we can usually decompose $\gamma$ into two subvectors $\gamma_{1}$ and $\gamma_{2}$, where $\gamma_{1}$ (of dimension $k_{1}$ ) is independent of $\beta$. We can then write

$$
\gamma_{1}=h_{1}\left(Y_{0}, X_{0}\right)
$$

The second subvector $\gamma_{2}$ (of dimension $k_{2}=k-k_{1}$ ) is, on the other hand, a function of $\beta$ as well as of $X_{0}$ and $Y_{0}$, hence

$$
\gamma_{2}=\bar{h}_{2}\left(Y_{0}, X_{0}, \beta\right)=h_{2}(\beta)
$$

To the extent that the vector of exogenous variables $(X)$ is known, and bearing in mind that the deterministic nature of the model is not at issue, we may simplify the notation and write the model in the compact form

$$
Y=\bar{g}(X, \beta)=g(\beta),
$$

where the functions $\bar{g}$ and $g$ are defined for a given base year (after calibration), while $g$ also treats the vector $X$ as given. This formalization and qualifications on the calibrated parameters will prove 
to be very useful in theoretical developments and even indispensable for the numerical derivations associated with some approaches presented in this paper.

Generally, we will be interested in the effects of one or several economic policies which modify the elements of the vector $X$. Solutions to the model $M$, obtained for different values of exogenous variables $X$ but a single estimate value of $\beta$ may be compared and incorporated into a decisionmaking process. In principle, $\beta$ must be estimated econometrically, and it is possible to associate measures of uncertainty (standard deviations, confidence regions) with it. However, this type of information is generally ignored in appraisals of the reliability of the results.

We also note that the difficulties associated with the calibration of CGE models are not explicitly considered by usual methods for sensitivity analysis. These methods only deal with the estimations of the vector $\beta$, not $\gamma$. Notice that, in CGE models, the dimension of the joint vector $\left(\beta^{\prime}, \gamma^{\prime}\right)^{\prime}$ may be very large and econometric estimation difficult, if not impossible. In fact, the number of parameters of a CGE model increases rapidly with the number of sectors and consumers. Statistical data for high levels of disaggregation are frequently not available. The number of parameters to estimate may easily surpass the size of the sample. Thus, calibration may be viewed as an estimation procedure for $\gamma$. It is clear that this procedure only yields point estimates and does not account for the uncertainty inherent in the estimation of the free parameters $\beta$, nor for that associated with the social-accounting matrix for the reference year [see Byron (1978) and Dawkins (1997)].

\section{Projection-based confidence sets}

In this section, we develop an approach that allows us to evaluate the uncertainty associated with the subvector of calibrated parameters, $\gamma_{2}$, deriving a confidence region from that of the vector of free parameters $\beta$. As in Abdelkhalek and Dufour (1998), we assume that we have a confidence region $C$ with level $1-\alpha$ for the parameter $\beta$. In other words, $C$ is a subset of $\mathbb{R}^{p}$ such that

$$
P[\beta \in C] \geq 1-\alpha
$$

where $0 \leq \alpha<1$. Two different interpretations may be put forward for the set $C$. First, we can assume that $C$ is a sampling (frequentist) confidence region based on previous statistical studies and observations, i.e. $C=C(Z)$ is a random subset of $\mathbb{R}^{p}$ generated by a sample $Z$ such that the probability that a given vector $\beta$ is contained within $C(Z)$ is greater than or equal to $1-\alpha$. Second, in other situations we may treat the parameter $\beta$ as stochastic and consider that $\beta \in C$ is a Bayesian confidence region for $\beta$. The arguments developed below are applicable under either of these two interpretations. The region $C$ of $\mathbb{R}^{p}$ may be discrete, compact, connected or continuous.

Let $h_{2}(C)$ represent the image of $C$ over a calibration function $h_{2}$ defined in equation (2.5):

$$
h_{2}(C)=\left\{\gamma_{2} \in \mathbb{R}^{k_{2}}: \gamma_{2}=h_{2}\left(\beta_{0}\right) \quad \text { for at least one } \beta_{0} \in C\right\} .
$$

Clearly, we have the implication:

$$
\beta \in C \Rightarrow h_{2}(\beta) \in h_{2}(C),
$$


hence

$$
P\left[\gamma_{2} \in h_{2}(C)\right] \geq P[\beta \in C] \geq 1-\alpha
$$

We see that $h_{2}(C)$ is a conservative confidence region for $\gamma_{2}$, with level greater than or equal to $1-\alpha$ [see Rao (1973, Section 7b.3, p. 473) or Gouriéroux and Monfort (1989, volume 2, pp. 243-250)]. ${ }^{1}$ In particular, when $C$ is a sampling confidence region for $\beta$, we have:

$$
P\left[h_{2}(\beta) \in h_{2}(C)\right] \geq P[\beta \in C] \geq 1-\alpha, \quad \forall \beta \in \Omega .
$$

We can also obtain individual confidence intervals for the elements $\gamma_{2 i}=h_{2 i}(\beta)$ of the vector $h_{2}(\beta)=\left(h_{21}(\beta), \ldots, h_{2 k_{2}}(\beta)\right)^{\prime}$. In fact, since

$$
h_{2}(\beta) \in h_{2}(C) \Rightarrow\left[h_{2 i}(\beta) \in h_{2 i}(C), \text { for } i=1, \ldots, k_{2}\right],
$$

we have:

$$
\begin{aligned}
P\left[\gamma_{2 j} \in h_{2 j}(C)\right] & \geq P\left[\gamma_{2 i} \in h_{2 i}(C), i=1, \ldots, k_{2}\right] \\
& \geq P\left[\gamma_{2} \in h_{2}(C)\right] \\
& \geq 1-\alpha, j=1, \ldots, k_{2} .
\end{aligned}
$$

Since the function $h_{2}$ is generally nonlinear, the set $h_{2}(C)$ may be difficult to determine or visualize. In particular, it is not usually an interval or an ellipse. Nonetheless, as shown in Abdelkhalek and Dufour (1998), relatively simple forms may be derived from fairly weak assumptions on the function $h_{2}$ and on the set $C$ representing the confidence region of $\beta .^{2}$ In fact, if we assume that $h_{2}$ is continuous and that $C$ is compact in $\mathbb{R}^{p}$, the confidence region $h_{2}(C)$ for $\gamma_{2}$ is also compact in $\mathbb{R}^{k_{2}}$, and the univariate confidence regions for the elements of $\gamma_{2}$ are compact in $\mathbb{R}$. If $h_{2}$ is continuous and $C$ is connected in $\mathbb{R}^{p}$, the confidence region $h_{2}(C)$ for $\gamma_{2}$ is also connected in $\mathbb{R}^{k_{2}}$ and the confidence regions for the elements of $\gamma_{2}$ are connected in $\mathbb{R}$, and thus take the form of intervals. Finally, if $h_{2}$ is continuous and if $C$ is also continuous (i.e. connected, closed and bounded) in $\mathbb{R}^{p}$, then the confidence region $h_{2}(C)$ for $\gamma_{2}$ is also continuous in $\mathbb{R}^{k_{2}}$, and the univariate confidence intervals are continuous in $\mathbb{R}$. In particular, in this case the individual confidence regions $h_{2 i}(C), i=1, \ldots, k_{2}$, assume the shape of closed and bounded intervals: $h_{2 i}(C)=\left[\gamma_{2 i}^{L}, \gamma_{2 i}^{U}\right]$, where $\gamma_{2 i}^{L}>-\infty$ and $\gamma_{2 i}^{U}<+\infty, i=1, \ldots, k_{2}$.

In general, we can always construct simultaneous confidence intervals for the different elements of $h_{2}(\beta)$. We simply consider the extreme values:

$$
h_{2 i}^{L}(C)=\inf \left\{h_{2 i}(\beta): \beta \in C\right\}, h_{2 i}^{U}(C)=\sup \left\{h_{2 i}(\beta): \beta \in C\right\}
$$

where $-\infty \leq \gamma_{2 i}^{L}<\infty$ and $-\infty<\gamma_{2 i}^{U} \leq \infty, i=1, \ldots, k_{2}$, . Since $\left[h_{2 i}(\beta) \in h_{2 i}(C), i=\right.$

\footnotetext{
${ }^{1}$ For further examples of the projection technique in econometrics, see Dufour (1989, 1990, 1997), Dufour and Kiviet (1996, 1998 ), Dufour and Jasiak (1998), Kiviet and Dufour (1997).

${ }^{2}$ These assumptions on $h_{2}$ are typical in CGE models.
} 


$$
\begin{aligned}
\left.1, \ldots, k_{2}\right] \Rightarrow\left[h_{2 i}^{L}(C) \leq h_{2 i}(\beta) \leq h_{2 i}^{U}(C)\right. & \left., i=1, \ldots k_{2}\right], \text { we have: } \\
P\left[h_{2 j}^{L}(C) \leq \gamma_{2 j} \leq h_{2 j}^{U}(C)\right] & \geq P\left[h_{2 i}^{L}(C) \leq \gamma_{2 i} \leq h_{2 i}^{U}(C), i=1, \ldots, k_{2}\right] \\
& \geq P\left[\gamma_{2 i} \in h_{2 i}(C), i=1, \ldots, k_{2}\right] \\
& \geq 1-\alpha, \text { for } j=1, \ldots, k_{2} .
\end{aligned}
$$

It is thus sufficient to minimize and maximize each element of $\gamma_{2}=h_{2}(\beta)$ subject to the constraint $\beta \in C$ to obtain (simultaneous) level $1-\alpha$ confidence intervals for all of them.

Using these results we can construct confidence regions for the endogenous variables of CGE models from the confidence regions of the two parameter vectors $\beta$ and $\gamma_{2}$ (free, and calibrated dependent on the free) or simply from those of the vector $\beta$ of free parameters, having eliminated the calibrated parameters depending on the free parameters while accounting for the uncertainty associated with them. This result allows us to substantially simplify the numerical procedures, especially when the dimension of vector $\gamma_{2}$ is large. We illustrate the process of building these confidence regions of type $\gamma_{2}(C)$ with an example in the following sections.

\section{Calibrated parameters for CES and CET functions}

To illustrate the approach proposed above, we will now perform a detailed analysis of the case of an Armington-type import function commonly used in CGE models. This general form, which can be subject to various interpretations, is used to model sectorial production, exports, portfolio composition (models with financial flows), etc. In other words, this example covers a large number of cases of calibration in the presence of free parameters (elasticities) in CGE models. This function is linearly homogenous in its arguments, the number of which depends upon the model (inputs or factors of production, origin of imports, markets for exports, substitutable financial assets). In our example we have an import model in which a consumer derives utility from consuming a composite good denoted $Q$. This good is comprised of imported goods $M$ and domestic goods $D$. The consumer's problem is to choose a combination of quantities $M$ and $D$ which minimizes overall expenditure, given the two prices $p_{M}$ and $p_{D}$ and the level $Q$. The Armington form of this CES function is given by

$$
Q=B\left[\delta M^{-\rho}+(1-\delta) D^{-\rho}\right]^{-\frac{1}{\rho}}
$$

To find a more direct interpretation, we let $\sigma=1 /(1+\rho)$, i.e. $\rho=(1-\sigma) / \sigma$. Equation (4.1) may then be rewritten:

$$
Q=B\left[\delta M^{\frac{\sigma-1}{\sigma}}+(1-\delta) D^{\frac{\sigma-1}{\sigma}}\right]^{\frac{\sigma}{\sigma-1}}
$$

where $B$ is a constant, $\delta$ a share parameter, and $\sigma$ a (constant) elasticity of substitution between imported and domestic goods. In our terminology, given the deterministic calibration procedures applied to this type of function in CGE models [see Mansur and Whalley (1984],) $B$ and $\delta$ are calibrated parameters while $\sigma$ (or $\rho$ ) is a free parameter estimated or borrowed from outside the 
model, independent of the data from the social-accounting matrix for the reference year. The firstorder condition associated with this problem is given by the equality between the price ratio for the two types of good and the marginal rate of substitution between imported and domestic goods:

$$
\frac{p_{D}}{p_{M}}=\left[\frac{(1-\delta)}{\delta}\right]\left(\frac{D}{M}\right)^{-\rho-1}
$$

or

$$
\frac{M}{D}=\left[\frac{\delta p_{D}}{(1-\delta) p_{M}}\right]^{\frac{1}{\rho+1}}=\left(\frac{\delta}{1-\delta}\right)^{\sigma}\left(\frac{p_{D}}{p_{M}}\right)^{\sigma} .
$$

This method of modelling imports, examined in detail by de Melo and Robinson (1989) and by Devarajan, Lewis and Robinson (1990), is extensively used in CGE models. ${ }^{3}$ This seems more realistic than the classic formulation with perfect substitutability between goods. The CES function is sufficiently tractable for the analytical derivations and the calibration of parameters, despite the fact that it introduces a free parameter.

To calibrate the parameters of this type of function in CGE models different techniques have been used (estimates, literature reviews, international comparisons, or arbitrary fixing) to assign a value $(\hat{\sigma})$ to the free parameter - the elasticity of substitution $(\sigma)$ in this case. This value is crucial and constitutes the first step of the calibration process. From the first order condition, [equation (4.4)], from the data for $Q_{0}, M_{0}$ and $D_{0}$, and from a normalization assumption imposed on the base-year prices, we derive: ${ }^{4}$

$$
\left(\frac{M_{0}}{D_{0}}\right)^{\frac{1}{\hat{\sigma}}}=\frac{\delta}{1-\delta}\left(\frac{p_{D_{0}}}{p_{M_{0}}}\right)
$$

yielding a unique estimate for $\delta$ given by

$$
\hat{\delta}=\frac{\frac{p_{M_{0}}}{p_{D_{0}}}\left(\frac{M_{0}}{D_{0}}\right)^{\frac{1}{\hat{\sigma}}}}{1+\frac{p_{M_{0}}}{p_{D_{0}}}\left(\frac{M_{0}}{D_{0}}\right)^{\frac{1}{\hat{\sigma}}}}=h_{21}(\hat{\sigma}) .
$$

Now it remains to calibrate the scale parameter $B$. From equation (4.2) and from the base-year data, we find:

$$
\hat{B}=Q_{0} /\left[\hat{\delta} M_{0}^{\frac{\hat{\sigma}-1}{\hat{\sigma}}}+(1-\hat{\delta}) D_{0}^{\frac{\hat{\sigma}-1}{\hat{\sigma}}}\right]^{\frac{\hat{\sigma}}{\hat{\sigma}-1}}=h_{22}(\hat{\sigma}) .
$$

In equations (4.6) and (4.7) the essential role played by the free parameter in determining the values of the other parameters appears clearly. From this deterministic approach to calibration, we seek

\footnotetext{
${ }^{3}$ For a review of general equilibrium studies having used these forms, see Decaluwé and Martens (1988).

${ }^{4}$ An assumption concerning the base-year prices is usually made in CGE models. All prices, except those which include taxes or subsidies, are normalized to one for the base year (i.e. are treated as indices).
} 
to construct confidence intervals for the two calibrated parameters, $\delta$ and $B$, given that of the free parameter $\sigma$. To achieve this we work, not with a point estimate for $\sigma, \hat{\sigma}$, but rather with a set estimate.

Moving from the definition for a continuous function of a confidence interval $C \subset \mathbb{R}$ for $\sigma$ given in expression (4.6) towards a subset $h_{21}(C) \subset \mathbb{R}$, we analytically illustrate the construction of what is to become a confidence interval for $\delta$. To simplify notation, we write:

$$
N(\sigma)=\frac{p_{M_{0}}}{p_{D_{0}}}\left(\frac{M_{0}}{D_{0}}\right)^{\frac{1}{\sigma}}=\frac{p_{M_{0}}}{p_{D_{0}}} e^{\frac{1}{\sigma} \ln \left(\frac{M_{0}}{D_{0}}\right),}
$$

hence

$$
\delta=h_{21}(\sigma)=\frac{N(\sigma)}{1+N(\sigma)} .
$$

We now wish to examine the behavior of the function $h_{21}$, particularly within the confidence interval $C$. From equation (4.9) we see that

$$
\frac{d \delta}{d \sigma}=\frac{N^{\prime}(\sigma)[1+N(\sigma)]-N^{\prime}(\sigma) N(\sigma)}{[1+N(\sigma)]^{2}}=\frac{N^{\prime}(\sigma)}{[1+N(\sigma)]^{2}}
$$

where

$$
N^{\prime}(\sigma)=\frac{d N}{d \sigma}=\frac{p_{M_{0}}}{p_{D_{0}}}\left[-\frac{1}{\sigma^{2}} \ln \left(\frac{M_{0}}{D_{0}}\right)\right]\left(\frac{M_{0}}{D_{0}}\right)^{\frac{1}{\sigma}} .
$$

So it is clear that the sign of $d \delta / d \sigma$ is the same as that of $d N / d \sigma$, i.e

$$
\operatorname{sgn}\left(\frac{d \delta}{d \sigma}\right)=\operatorname{sgn}\left(\frac{d N}{d \sigma}\right)=\operatorname{sgn}\left[-\ln \left(\frac{M_{0}}{D_{0}}\right)\right]=\operatorname{sgn}\left[\ln \left(\frac{D_{0}}{M_{0}}\right)\right]
$$

where $\operatorname{sgn}(x)=1$ if $x>0, \operatorname{sgn}(x)=-1$ if $x<0$, and $\operatorname{sgn}(x)=0$ if $x=0$. If $D_{0}>M_{0}$, then $(d \delta / d \sigma)>0$ and vice versa. This result, which we have never encountered in the literature on CGE models, is quite surprising and, depending on the context, it may have interesting economic interpretations. We see that the function $h_{21}$ is continuous and strictly monotonic. If we assume that the confidence interval for $\sigma(C)$ is a closed bounded set of the form $[\underline{\sigma}, \bar{\sigma}]$, with level $1-\alpha$, then one of the two intervals $\left[h_{21}(\underline{\sigma}), h_{21}(\bar{\sigma})\right]$ and $\left[h_{21}(\bar{\sigma}), h_{21}(\underline{\sigma})\right]$ is a level $1-\alpha$ confidence interval for the calibrated parameter $\delta .{ }^{5}$ In other words, one of the following implications must hold:

$$
\begin{aligned}
& P(\sigma \in[\underline{\sigma}, \bar{\sigma}]) \geq 1-\alpha \Rightarrow P\left(\delta \in\left[h_{21}(\underline{\sigma}), h_{21}(\bar{\sigma})\right]\right) \geq 1-\alpha, \\
& P(\sigma \in[\underline{\sigma}, \bar{\sigma}]) \geq 1-\alpha \Rightarrow P\left(\delta \in\left[h_{21}(\bar{\sigma}), h_{21}(\underline{\sigma})\right]\right) \geq 1-\alpha .
\end{aligned}
$$

In addition to the share parameter $\delta$, a similar analysis may be performed on the scale parameter $B$.

\footnotetext{
${ }^{5}$ A study by Reinert and Roland-Holst (1992) of 163 sectors of the U.S. economy reveals that this elasticity $\sigma$ falls between 0.14 and 3.49 .
} 
This work is analytically not as simple as that on $\delta$, but remains feasible numerically (see Section $5)$.

Since the calibration procedure is usually performed in a pre-defined order, accounting for the uncertainty associated with the calibrated parameters depending on the free parameters is tantamount to clearly specifying the confidence regions for the free parameters of the model.

\section{Application to CGE models of Morocco}

In this section, we apply the projection method described in Section 3 to the construction of confidence sets for the calibrated parameters (which depend on free parameters) in the context of two different models for Morocco. The first one is a submodel of a type 1-2-3 CGE model [Devarajan, Lewis and Robinson (1990)] studied in Abdelkhalek (1994) and Abdelkhalek and Dufour (1998). The second one is a submodel of a two-sector model (agriculture and industry) used by Abdelkhalek and Martens (1996). Both models include imported goods $(M)$ and locally produced goods $(D)$, which are aggregated through an Armington-type CES function. The Moroccan reference year data come from 1985 for the first model and from 1990 for the second model. Calculations and optimizations were performed using the GAMS-MINOS program [see Brooke and al. (1988)]. ${ }^{6}$

Given the reference-year values $Q_{0}, M_{0}, D_{0}, p_{M_{0}}$ and $p_{D_{0}}$ and a level $1-\alpha$ confidence region $C$ for the free parameter $\sigma$, the confidence intervals are obtained by minimizing and maximizing the values of the calibrated parameters subject to the restriction that the free parameter remains in its confidence region. Note the confidence set $C$ for $\sigma$ may be truncated to only contain values in a set $C_{0}$ of economically admissible values; the resulting smaller confidence set $C \cap C_{0}$ has the same level as the original set $C$ [see Abdelkhalek and Dufour (1998)]. The set $C \cap C_{0}$ to which $\sigma$ is restricted is usually specified through a set of nonlinear inequalities. More precisely, we solve the following problems:

$$
\begin{aligned}
\text { minimize and maximize } \delta & =h_{21}(\sigma) \equiv \frac{\left(p_{M_{0}} / p_{D_{0}}\right)\left(M_{0} / D_{0}\right)^{\frac{1}{\sigma}}}{1+\left(p_{M_{0}} / p_{D_{0}}\right)\left(M_{0} / D_{0}\right)^{\frac{1}{\sigma}}} \\
\text { subject to } \sigma & \in C \cap C_{0} ; \\
\text { minimize and maximize } B & =h_{22}(\sigma)=Q_{0} /\left[\delta M_{0}^{\frac{\sigma-1}{\sigma}}+(1-\delta) D_{0}^{\frac{\sigma-1}{\sigma}}\right]^{\frac{\sigma}{\sigma-1}} \\
\text { subject to } \delta & =h_{21}(\sigma) \text { and } \sigma \in C \cap C_{0} .
\end{aligned}
$$

It is also useful to remember that the price of the imported good is given by the equation

$$
p_{M_{0}}=p_{w m 0}\left(1+t_{m}\right) E_{0}
$$

\footnotetext{
${ }^{6}$ The program is supplied in Appendix B.
} 
TABLE 1: Moroccan data used in the calibrations ${ }^{a}$

\begin{tabular}{|l||c|c|c|}
\hline Variables & SAM 1985 & $\begin{array}{c}\text { SAM 1990 } \\
\text { Agriculture }\end{array}$ & $\begin{array}{c}\text { SAM 1990 } \\
\text { Industry }\end{array}$ \\
\hline \hline$Q_{0}$ & 252653 & 69589.32 & 317195.92 \\
\hline$M_{0}$ & 42806 & 4248 & 59327.9 \\
\hline$D_{0}$ & 209847 & 65341.32 & 257868.02 \\
\hline$T A X M_{0}$ & 9046.7 & -391.79 & 10048.1 \\
\hline$t m$ & 0.211 & -0.0922 & 0.16936 \\
\hline$P D_{0}$ & 1 & 1 & 1 \\
\hline$P W M_{0}$ & 1 & 1 & 1 \\
\hline$E_{0}$ & 1 & 1 & 1 \\
\hline$P M_{0}$ & 1.211 & 0.9078 & 1.16936 \\
\hline$\sigma$ & {$[0.7838,2.0809]$} & {$[0.5,4.5]$} & {$[0.5,4.5]$} \\
\hline
\end{tabular}

${ }^{a}$ SAM: social accounting matrix. Data for $\mathrm{Q}_{0}, \mathrm{M}_{0}, \mathrm{D}_{0}, \mathrm{TAXM}_{0}$, are in millions of dirhams and were obtained from GREI (1992) for 1985 and from Abdelkhalek and Martens (1996) for 1990. The confidence intervals for $\sigma$ are econometric estimates for 1985 from Abdelkhalek and Dufour (1998) , while those for 1990 are subjectively determined although consistent with the elasticity values reported by Reinert and Roland-Holst (1992).

where $p_{w m 0}$ is the international price of imports, $t_{m}$ is the tariff on imports and $E_{0}$ is the nominal exchange rate, evaluated at the reference year.

The Moroccan data used in our calculations are summarized in Table 1, while the confidence intervals for calibrated parameters $\delta$ and $B$ appear in Table 2. For the one-sector model calibrated on the reference year 1985, we used for the free parameter $\sigma$ the $95 \%$ confidence interval [0.7838, 2.0809], which is based on the estimations presented in Abdelkhalek and Dufour (1998). The results in Table 2 indicate that this interval on $\sigma$ gets translated into the intervals $[0.137,0.361]$ and $[1.568$, $1.862]$ for $\delta$ and $B$ respectively. These intervals show there is a non-negligible uncertainty on the calibrated parameters even though the confidence intervals remain remarkably tight and informative. For the two-sector model (calibrated on 1990 data), we used the wider interval [0.5, 4.5]. The latter was a subjectively determined, although quite consistent with the range of values reported by Reinert and Roland-Holst (1992) for similar elasticities. Not surprisingly, we find in this case wider (although still informative) intervals for the sectorial parameters $\delta$ and $B$ associated with agriculture and industry: $\delta \in[0.004,0.331]$ and $B \in[1.010,1.658]$ for the agricultural sector, $\delta \in$ $[0.058,0.458]$ and $B \in[1.470,1.988]$ for the industrial sector.

\section{Confidence regions based on equations with disturbances}

In this section, we present an approach for constructing confidence regions for the calibrated parameters of the model, going beyond the deterministic framework which is typical of CGE models. This method introduces randomness, and thus uncertainty, into some or all of the model equations 
TABLE 2: Confidence intervals for $\delta$ and $B$

\begin{tabular}{|l||c|c|c|c|c|c|}
\hline \multicolumn{1}{|l||}{ Parameter } & \multicolumn{3}{|c|}{$\delta$} & \multicolumn{3}{c|}{$B$} \\
\hline \hline Confidence bounds & Lower & Upper & Range & Lower & Upper & Range \\
\hline 1985 & 0.137 & 0.361 & 0.224 & 1.568 & 1.862 & 0.294 \\
\hline Agriculture 1990 & 0.004 & 0.331 & 0.327 & 1.010 & 1.658 & 0.648 \\
\hline Industry 1990 & 0.058 & 0.458 & 0.400 & 1.470 & 1.988 & 0.518 \\
\hline \hline
\end{tabular}

used for the deterministic calibration, in order to construct simultaneous confidence regions for the calibrated parameters.

Before generalizing the proposed approach (Section 7), we shall discuss the simple case of a Cobb-Douglas production function with constant returns to scale for the factors labor and capital. Since primary inputs are required in the production process, "production" is defined as value added. This type of modelling and these functional forms are frequently used in CGE models because of the simplicity, of the resulting expressions and calibration. The general form of this type of production function in the presence of several categories of the labor input and a single factor capital per sector is given by:

$$
X_{i}=A_{i} \prod_{l} L_{i, l}^{\delta_{i, l}} K_{i}^{\left(1-\sum_{l} \delta_{i, l}\right)}
$$

where $X_{i}$ is production (or value added) in sector $i, A_{i}$ is a scale parameter, $L_{i, l}$ is the quantity of the type $l$ labor used in sector $i, K_{i}$ is the quantity of capital used in sector $i$, and $\delta_{i, l}$ the elasticity of production of type $l$ labor in sector $i$. All of the following presentation may be derived from equation (6.1). In order to simplify the notation, we shall ignore the index $i$ representing the sector and consider only one type of labor. Thus, production function (6.1) assumes the following simpler form:

$$
X=A L^{\delta} K^{(1-\delta)}
$$

In standard CGE models certain assumptions are made concerning the structure of markets. These assumptions facilitate accounting for the behavior of agents, particularly of firms, in each sector of the economy. This information is used to derive factor demands from profit maximization programs. Since our concern here is primarily econometric, we shall assume that the sector is perfectly competitive. The first-order conditions are:

$$
p X \delta=w L
$$

where $p$ is the price of good $X$ (or the price of the value added), and $w$ is the wage rate of labor. To calibrate the parameters of this type of function, model builders only require reference data for the base year from a social-accounting matrix. No information on the free parameters is required. The necessary data for the reference year comprise: the sectorial value of production (or the value 
added, $\left.p_{0} X_{0}\right)$ and the corresponding total wage bill $\left(w_{0} L_{0}\right)$. Equation (6.3) then yields a unique estimate for $\delta$, based on a single observation (the base year), owing to the deterministic nature of the model:

$$
\hat{\delta}=\frac{w_{0} L_{0}}{p_{0} X_{0}}
$$

From this estimate for $\delta$ and from equation (6.2), we can derive an estimate for the scale coefficient of the production function $(A):^{7}$

$$
\hat{A}=\frac{X_{0}}{L_{0}^{\hat{\delta}} K_{0}^{(1-\hat{\delta})}} .
$$

Given the aforementioned assumptions, it is obvious that this calibration procedure may be applied to production functions of this type for all sectors and factors of production.

We now consider a production function (6.2) incorporating a stochastic disturbance term applicable to this example as well as similar ones. The notion of introducing random shocks into some of the equations of a CGE model (those used in the deterministic calibration) is not entirely new. Mansur and Whalley (1984) proposed stochastic forms for CGE models which allow the estimation of the parameters, provided there is a sufficient number of observations. However, this is generally not possible (e.g. when the data only pertains to a single base year). This is the case we are concerned with here. Assume that the production function (6.2) and the first-order condition (6.3) are stochastic, as follows:

$$
\begin{aligned}
X & =A L^{\delta} K^{(1-\delta)} e^{u}, \\
p X \delta & =w L e^{v},
\end{aligned}
$$

where $(u, v)$ is a vector of random variables with a known distribution that can be simulated. Two equations can be written for the base-year data:

$$
\begin{aligned}
X_{0} & =A L_{0}^{\delta} K_{0}^{(1-\delta)} e^{u_{0}}, \\
p_{0} X_{0} \delta & =w_{0} L_{0} e^{v_{0}}
\end{aligned}
$$

where $A$ and $\delta$ are the two unknown parameters. We then deduce:

$$
\begin{aligned}
\delta & =\frac{w_{0} L_{0}}{p_{0} X_{0}} e^{v_{0}}, \\
A & =\frac{X_{0}}{L_{0}^{\delta} K_{0}^{(1-\delta)} e^{u_{0}}} .
\end{aligned}
$$

The equations for the deterministic framework derived in (6.4) and (6.5) no longer obtain, because they only hold true when the random errors $u$ and $v$ are identically zero. In the stochastic model

\footnotetext{
${ }^{7}$ Notice that we have again normalized the prices, allowing us to impute the value $p_{0} X_{0}$ to the volume $X_{0}$.
} 
these two equations yield estimators for $\delta$ and $A$ respectively. Thus, by definition,

$$
\hat{\delta}_{0}=\frac{w_{0} L_{0}}{p_{0} X_{0}}
$$

irrespective of $A$. Let

$$
A_{0} \equiv A_{0}(\delta)=\frac{X_{0}}{L_{0}^{\delta} K_{0}^{(1-\delta)}}
$$

In particular, for $\hat{\delta}_{0}$ we obtain:

$$
\hat{A}_{0}=\hat{A}_{0}\left(\hat{\delta}_{0}\right)=\frac{X_{0}}{L_{0}^{\hat{\delta}_{0}} K_{0}^{\left(1-\hat{\delta}_{0}\right)}} .
$$

From equations (6.11) and (6.14) we find

$$
\frac{\hat{A}_{0}}{A}=\frac{L_{0}^{\delta} K_{0}^{(1-\delta)} e^{u_{0}}}{L_{0}^{\hat{\delta}_{0}} K_{0}^{\left(1-\hat{\delta}_{o}\right)}}
$$

or, equivalently,

$$
\frac{\hat{A}_{0}}{A}=\left(\frac{K_{0}}{L_{0}}\right)^{\left(\hat{\delta}_{0}-\delta\right)} e^{u_{0}}
$$

which, upon taking logs, yields

$$
\ln \left(\hat{A}_{0}\right)-\ln (A)=\left(\hat{\delta}_{0}-\delta\right) \ln \left(\frac{K_{0}}{L_{0}}\right)+u_{0} .
$$

Furthermore, from equations (6.10) and (6.12) we derive:

$$
\frac{\hat{\delta}_{0}}{\delta}=\frac{1}{e^{v_{0}}}
$$

or

$$
\ln (\delta)-\ln \left(\hat{\delta}_{0}\right)=v_{0}
$$

From either equation $(6.18)$ or $(6.19)$, we see that $\hat{\delta}_{0} / \delta$ or $\left[\ln \left(\hat{\delta}_{0}\right)-\ln (\delta)\right]$ are pivotal functions for the parameter $\delta$. A pivotal function for $\delta$ is any stochastic function $Z$ defined on the observations and on the parameter $\delta$ such that the distribution of $Z$ does not depend on $\delta$ despite the fact that this parameter appears in the arguments. ${ }^{8}$ When we have a pivotal function which can be

\footnotetext{
${ }^{8}$ See Gouriéroux and Monfort (1989, volume 2, p. 24), for example.
} 
inverted to isolate the parameter of interest, we can construct confidence intervals for that parameter. This is the procedure we shall use here. Given any known distribution of the vector $\left(u_{0}, v_{0}\right)$, simulated confidence intervals may be constructed for the parameters $\delta$ and $A$ or for functions of these parameters. Notice that, unlike Mansur and Whalley (1984), we require neither that $\left(u_{0}, v_{0}\right)$ be normally distributed nor $u_{0}, v_{0}$ be independent. However, by making these assumptions we benefit from significant practical simplifications.

In the case we are about to examine, notice that $\hat{\delta}_{0} / \delta$ only depends upon $v_{0}$ (and not on $u_{0}$ ). We can write

$$
P\left(\hat{\delta}_{0} / \delta \geq c_{\alpha}\right)=P\left(e^{-v_{0}} \geq c_{\alpha}\right)=\alpha
$$

where $\alpha$ is a constant fixed a priori and $c_{\alpha}$ is the corresponding critical value, which can be derived from the theoretical or simulated distribution of $v_{0}$. Thus we have

$$
P\left(\hat{\delta}_{0} / \delta \leq c_{\alpha}\right)=1-\alpha
$$

and

$$
\Gamma_{\delta}=\left\{\delta \in \mathbb{R}: \hat{\delta}_{0} / \delta \leq c_{\alpha}\right\}=\left\{\delta \in \mathbb{R}: c_{\alpha} \delta \geq \frac{w_{0} L_{0}}{p_{0} X_{0}}\right\}
$$

is a level $1-\alpha$ confidence interval for the parameter $\delta$.

Similarly, we can construct a confidence interval for the parameter $A$. In a first instance, if we assume that $\delta$ is known and that the unknown parameter is the scale parameter $A$, we can use equations (6.11) and (6.13) to derive:

$$
e^{u_{0}}=A_{0} / A
$$

which, as before, yields a pivotal function for $A$ and allows the construction of a confidence interval for this parameter. Nonetheless, as $\delta$ is generally unknown, this procedure may not be very useful. The two equations (6.16) and (6.17) cannot yield a pivotal function for $A$. Even if we use equations (6.17) and (6.18) to eliminate $\delta$, the ensuing expression

$$
u_{0}=\ln \left(\hat{A}_{0}\right)-\ln (A)+\hat{\delta}_{0}\left(e^{v_{0}}-1\right) \ln \left(K_{0} / L_{0}\right)
$$

does not constitute a pivotal function for $A$.

When $\delta$ is unknown it is thus difficult (if not impossible) to construct a similar confidence interval for $A$. Nonetheless, it is possible to find a two-dimensional pivotal function for the twodimensional parameter $(A, \delta)$. Using equations (6.17) and (6.19) we may write:

$$
W=\left(\begin{array}{c}
u_{0} \\
v_{0}
\end{array}\right)=\left(\begin{array}{c}
\ln \left(\hat{A}_{0}\right)-\ln (A)+\left(\delta-\hat{\delta}_{0}\right) \ln \left(K_{0} / L_{0}\right) \\
\ln (\delta)-\ln \left(\hat{\delta}_{0}\right)
\end{array}\right)
$$


Since the distribution of the vector $\left(u_{0}, v_{0}\right)$ is fixed and known by assumption, we indeed have a pivotal function for the pair $[\ln (A), \delta]$. Since the covariance matrix, $\Omega$, of this vector is known, we can calculate the following statistic:

$$
T\left(u_{0}, v_{0}\right)=W^{\prime} \Omega^{-1} W .
$$

By assumption, this distribution can be simulated. In particular, if we assume that the distribution of vector $\left(u_{0}, v_{0}\right)$ is multivariate normal, this distribution will be $\chi^{2}(2)$. Consequently, we can find the point $c_{\alpha}$ such that

$$
P\left[T\left(u_{0}, v_{0}\right) \leq c_{\alpha}\right]=P\left[W^{\prime} \Omega^{-1} W \leq c_{\alpha}\right]=1-\alpha,
$$

where $\alpha$ is a level fixed a priori. Finally, a level $1-\alpha$ confidence region for the pair $(A, \delta)$ is given by

$$
\Gamma_{(\delta, A)}=\left\{(\delta, A) \in \mathbb{R}^{2}: W^{\prime} \Omega^{-1} W \leq c_{\alpha}\right\} .
$$

The procedure described in this Section for Cobb-Douglas production functions covers a number of cases used in CGE models. Similar cases may be dealt with using the same techniques to construct confidence regions for all the calibrated parameters of a model.

\section{Confidence regions from equations with disturbances: general approach}

In this section, we generalize the approach based on simulations to construct confidence regions, compatible with an underlying deterministic calibration, for all the calibrated parameters of a CGE model. To accomplish this, we revert to the first three equations describing the basic structure of the problem, given in Section 2:

$$
\begin{aligned}
Y & =M(X, \beta, \gamma) \\
Y_{0} & =M\left(X_{0}, \beta, \gamma\right), \\
\gamma & =H\left(Y_{0}, X_{0}, \beta\right)=h(\beta) .
\end{aligned}
$$

To begin, assume that there are no free parameters in the model, i.e. that all parameter values can be derived from the reference-year data (such as a social-accounting matrix). We shall return to examine the case with free parameters. Equations $(7.1),(7.2)$ and (7.3) can thus be simplified to:

$$
\begin{aligned}
Y & =\bar{M}(X, \gamma) \\
Y_{0} & =\bar{M}\left(X_{0}, \gamma\right), \\
\gamma & =\bar{H}\left(Y_{0}, X_{0}\right) .
\end{aligned}
$$

Contrary to what is implied by the general formulation of the model as expressed above, the calibration process usually only uses some of the equations of the model. Generally, these are the equations 
which specify the behavior of agents, the corresponding first-order conditions, and sometimes certain equilibrium conditions. The remaining equilibrium conditions, the accounting identities, and the definitions are not used in the calibration. For this reason, and because it is the econometric aspect of calibration that we are interested in, we may rewrite the calibration sub-system as

$$
Y^{S}=S\left(X^{S}, \gamma\right)
$$

hence

$$
\gamma=\bar{H}_{S}\left(Y_{0}^{S}, X_{0}^{S}\right)
$$

where $Y_{0}^{S}$ and $X_{0}^{S}$ respectively represent the model's subvectors of endogenous and exogenous variables used for calibration. So far we have only been working within the deterministic framework of CGE models.

The stochastic extension to the model which we are about to consider consists of associating additive error terms (for the demand functions) and multiplicative error terms (for the production or similar functions) with the system of equations in (7.7), as proposed by Mansur and Whalley (1984). Let the relation in (7.7) include a vector of additive disturbances $U:^{9}$

$$
Y^{S}=S\left(X^{S}, \gamma\right)+U
$$

where $U$ is a vector of random terms of the same dimension as $Y^{S}$, with any distribution which is known and can be simulated. In particular, the distribution of $U$ need not be normal. ${ }^{10}$ With no loss of generality, we may assume that the expectation of $U$ is zero, and that the covariance is known and equal to $\Sigma$. It is thus clear that the deterministic framework has been abandoned, albeit within the context of calibration.

As in equation (7.5), but now including the random term, we can write:

$$
Y_{0}^{S}=S\left(X_{0}^{S}, \gamma\right)+U_{0}
$$

where $U_{0}$ has the same distribution as $U$. As in the case of deterministic calibration, we derive:

$$
\gamma=\bar{H}_{S}\left(Y_{0}^{S}-U_{0}, X_{0}^{S}\right)
$$

Consequently, equation (7.8) no longer obtains. It is only true when $U_{0}$ is a vector of zeros. Thus, in this stochastic context the function $\bar{H}_{S}\left(Y_{0}^{S}, X_{0}^{S}\right)$ yields an estimator $\hat{\gamma}_{0}$ for $\gamma$ :

$$
\hat{\gamma}_{0}=\bar{H}_{S}\left(Y_{0}^{S}, X_{0}^{S}\right) \text {. }
$$

\footnotetext{
${ }^{9}$ Letting this vector enter the equation multiplicatively does not affect our results (see the formulation in Appendix A).

${ }^{10}$ The elements of $U$ may be degenerate at zero if by their economic nature the equations used in the deterministic calibration do not contain random disturbances.
} 
This, combined with the definition of this estimator (7.7) yields:

$$
Y_{0}^{S}=S\left(X_{0}^{S}, \hat{\gamma}_{0}\right)
$$

The goal of this step in the proposed procedure is to derive the scalar or vector relationships from equations (7.10) and (7.13) (possibly after performing some algebraic transformations as required by certain equation structures), allowing us to solve for some or all of the elements of $U$ (or for some algebraic transformation of the vector $U$ or its elements). Since the distribution of $U$ is known, these transformations allow us to derive a pivotal function for $\gamma$. Using equations (7.10) and (7.13) we easily find the following:

$$
W\left(X_{0}^{S}, \hat{\gamma}_{0}, \gamma\right)=S\left(X_{0}^{S}, \hat{\gamma}_{0}\right)-S\left(X_{0}^{S}, \gamma\right)=U_{0} .
$$

Since the distribution of $U_{0}$ is known (by assumption), the left-hand side of expression (7.14) defines a pivotal function for the parameter $\gamma$. Moreover, in a calibration system like the one defined in equations (7.7) and (7.8) the number of calibrated parameters contained in $\gamma$ ( $k$ in our case) is always equal to the number of equations. In other words, $k$ is the dimension of $\gamma, Y^{S}$, and $U$. Lau, commenting on Mansur and Whalley (1984), makes a similar remark. If $\Sigma$ is the covariance matrix of $U$, we may simulate the pivotal function $T(\gamma)$ as follows:

$$
T(\gamma)=W\left(X_{0}^{S}, \hat{\gamma}_{0}, \gamma\right)^{\prime} \Sigma^{-1} W\left(X_{0}^{S}, \hat{\gamma}_{0}, \gamma\right)=U^{\prime} \Sigma^{-1} U
$$

We find $c_{\alpha}$ such that:

$$
P\left[T(\gamma) \leq c_{\alpha}\right]=P\left[U^{\prime} \Sigma^{-1} U \leq c_{\alpha}\right]=1-\alpha .
$$

Finally, the confidence region we seek for $\gamma$ is defined as:

$$
\Gamma_{\gamma}=\left\{\gamma \in \mathbb{R}^{k}: T(\gamma) \leq c_{\alpha}\right\}
$$

In practice, the appropriate critical point $c_{\alpha}$ may not be analytically computable. To obtain an exact confidence region, we may fall back on Monte-Carlo tests [Dwass (1957), Barnard (1963), Dufour and Kiviet (1996, 1998), Dufour (1995)]. By assumption, it is possible to generate $N$ independent and identically distributed representations, $U_{1}, \ldots, U_{N}$, of the vector $U$ using MonteCarlo techniques and, by extension, $N$ independent and identically distributed representations, $T_{i}=$ $U_{i}^{\prime} \Sigma^{-1} U_{i}, i=1, \ldots, N$, of the pivotal function, $T(\gamma)$. Thus, the variables $T(\gamma), T_{1}, \ldots, T_{N}$, are independent and identically distributed.

Now consider the functions

$$
\hat{F}_{N}(x)=\frac{1}{N}\left[\sum_{i=1}^{N} s\left(x-T_{i}\right)\right], \quad \hat{q}_{N}(x)=\frac{N \hat{F}_{N}(x)+1}{N+1},
$$

where $s(x)=1$ if $x \geq 0$ and $s(x)=0$ if $x<0$. If we assume that the distribution of $T(\gamma)$ is 
continuous, we easily see that

$$
P\left\{\hat{q}_{N}[T(\gamma)] \leq 1-\alpha\right\}=\frac{I[(1-\alpha)(N+1)]}{N+1}, \quad \text { for } \alpha \in(0,1),
$$

where $I[x]$ is the largest integer less than or equal to $x$. In particular, if $(1-\alpha)(N+1)$ is an integer, we have:

$$
P\left\{\hat{q}_{N}[T(\gamma)] \leq 1-\alpha\right\}=1-\alpha, \quad \alpha \in(0,1)
$$

It follows that the set

$$
\Gamma_{\gamma}(N)=\left\{\gamma: \hat{q}_{N}[T(\gamma)] \leq 1-\alpha\right\}
$$

is a level $1-\alpha$ confidence region for $\gamma$.

So far we have assumed that the model contains calibrated, but not free, parameters. Now we shall consider the case in which both parameter types appear in the model. This amounts to combining a priori information on the free parameters with the distributions of random variables in the model to construct confidence intervals for the calibrated parameters. If we can condition on a point estimate of the free parameters, we revert to the case discussed earlier in this section since the conditioning eliminates the extrinsic uncertainty. However, if the two sources of uncertainty are jointly accounted for, the approach proposed for the case with no free parameter changes, but not fundamentally. In fact, alongside the equations used in the deterministic calibration, and which are now considered to contain disturbances which are either additive or multiplicative, we now add not a point estimate of the vector of free parameters nor a confidence region for this vector, but rather an estimator with a distribution that is known a priori. ${ }^{11}$

For example, consider the case of constant elasticity of substitution or transformation functions, like the Armington function we examined in Section 4. We let the function and its associated firstorder condition contain two multiplicative errors in the following manner:

$$
\begin{aligned}
Q & =B\left[\delta M^{\frac{\sigma-1}{\sigma}}+(1-\delta) D^{\frac{\sigma-1}{\sigma}}\right]^{\frac{\sigma}{\sigma-1}} e^{u}, \\
\frac{M}{D} & =\left(\frac{\delta}{1-\delta}\right)^{\sigma}\left(\frac{p_{D}}{p_{M}}\right)^{\sigma} e^{v}
\end{aligned}
$$

where $u$ and $v$ are random variables. The vector $(u, v)$ need not have a normal distribution, nor is it required that $u$ and $v$ be independent. Moreover, we assume an a priori distribution for the estimator $\hat{\sigma}$ of the free parameter $\sigma$. If we have reasons to suspect that the distribution of this parameter is not independent of the vector $(u, v)$, we need to consider the joint distribution of $(\hat{\sigma}, u, v)$, and its covariance matrix must be estimated before we can perform simulations. It remains to find the pivotal function for $\delta$ and $B-$ not a negligible task from an analytical perspective. The distribution of this pivotal function will be related to that of the vector $(\hat{\sigma}, u, v)$.

\footnotetext{
${ }^{11}$ Such hypotheses are often made in sensitivity analysis of CGE models [see, for example, Harrison and Vinod (1992) and Dawkins (1997)].
} 


\section{Conclusion}

In this paper we have formalized the concept of calibration in CGE models and developed two statistical methods for constructing confidence intervals for the calibrated parameters of these models. One is based on a projection technique which allows the construction of confidence sets for calibrated parameters. It greatly facilitates the construction of confidence regions for the endogenous variables of the model. After discussing numerical methods for implementing the approach developed, the latter was illustrated on a CES function (the Armington function) frequently used in CGE models. The second method allows one to extend the usual deterministic specification of CGE models by adding stochastic disturbances to the equations of the model and then to construct corresponding confidence sets for calibrated parameters using simulation techniques. This method uses the classical concept of a pivotal function for a parameter. The general nature of this procedure allows it to apply to several cases that frequently occur in CGE models. We used a Cobb-Douglas production function to illustrate it. These two new methods of statistical inference in CGE models go part way to solving one of the most serious econometric problems associated with these models and provide a way to manage the issue of uncertainty in the calibration of CGE models. 


\section{A. Multiplicative disturbances}

Generally in economics, equations are assigned multiplicative stochastic terms to assure nonnegativity of the endogenous variables. We use this assertion in the proof. Let equation (7.7) contain multiplicative errors disturbances as follows:

$$
Y^{s}=U S\left(X^{s}, \gamma\right)
$$

or

$$
Y^{s \prime}=S\left(X^{s}, \gamma\right)^{\prime} U^{\prime}
$$

where $U$ is a square diagonal matrix whose dimension equals the number of elements of $Y^{s}$. The distribution of the elements of $U$ is known and can be simulated, it does not need to be normal. ${ }^{12}$ With no loss of generality, we may assume that the expectation of the elements of $U$ is unity, and the known covariance matrix is denoted $\Sigma$. Considering our comment on the non-negativity of the endogenous variables, and thus of the random terms associated with the equations, (A.1) may be written:

$$
\ln \left(Y_{i}^{s}\right)=\ln \left(U_{i}\right)+\ln \left[S_{i}\left(X^{s}, \gamma\right)\right], \quad i=1, \ldots, k .
$$

With this form, if the disturbance terms were additive the logarithmic transformation would not be performed. With the appropriate changes in variables we revert to the additive disturbances dealt with in the text.

\footnotetext{
${ }^{12}$ The elements of $U$ may be degenerate at 1 if by their economic nature the equations used in the deterministic calibration do not contain random disturbances.
} 


\section{B. GAMS-MINOS program for the applications}

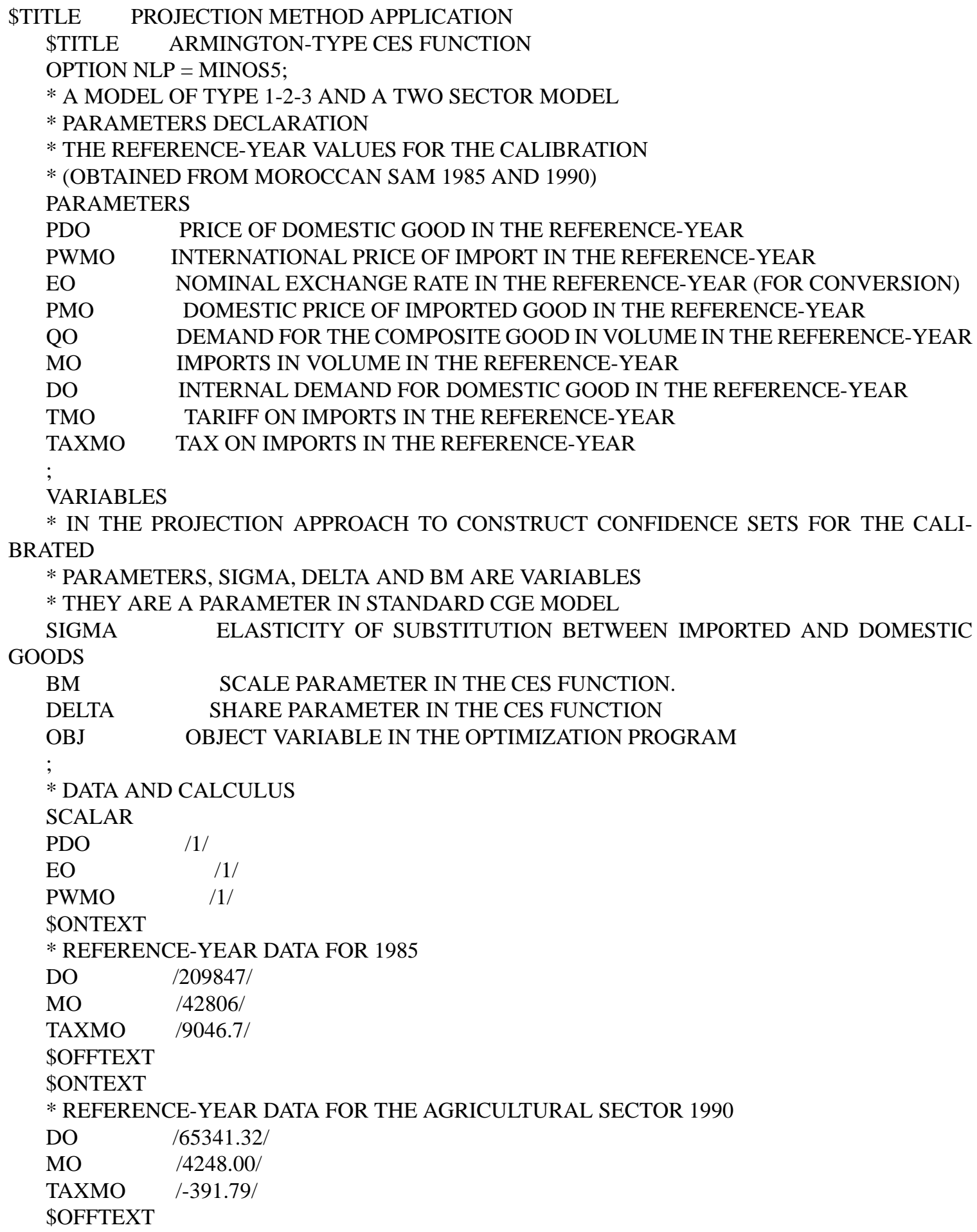




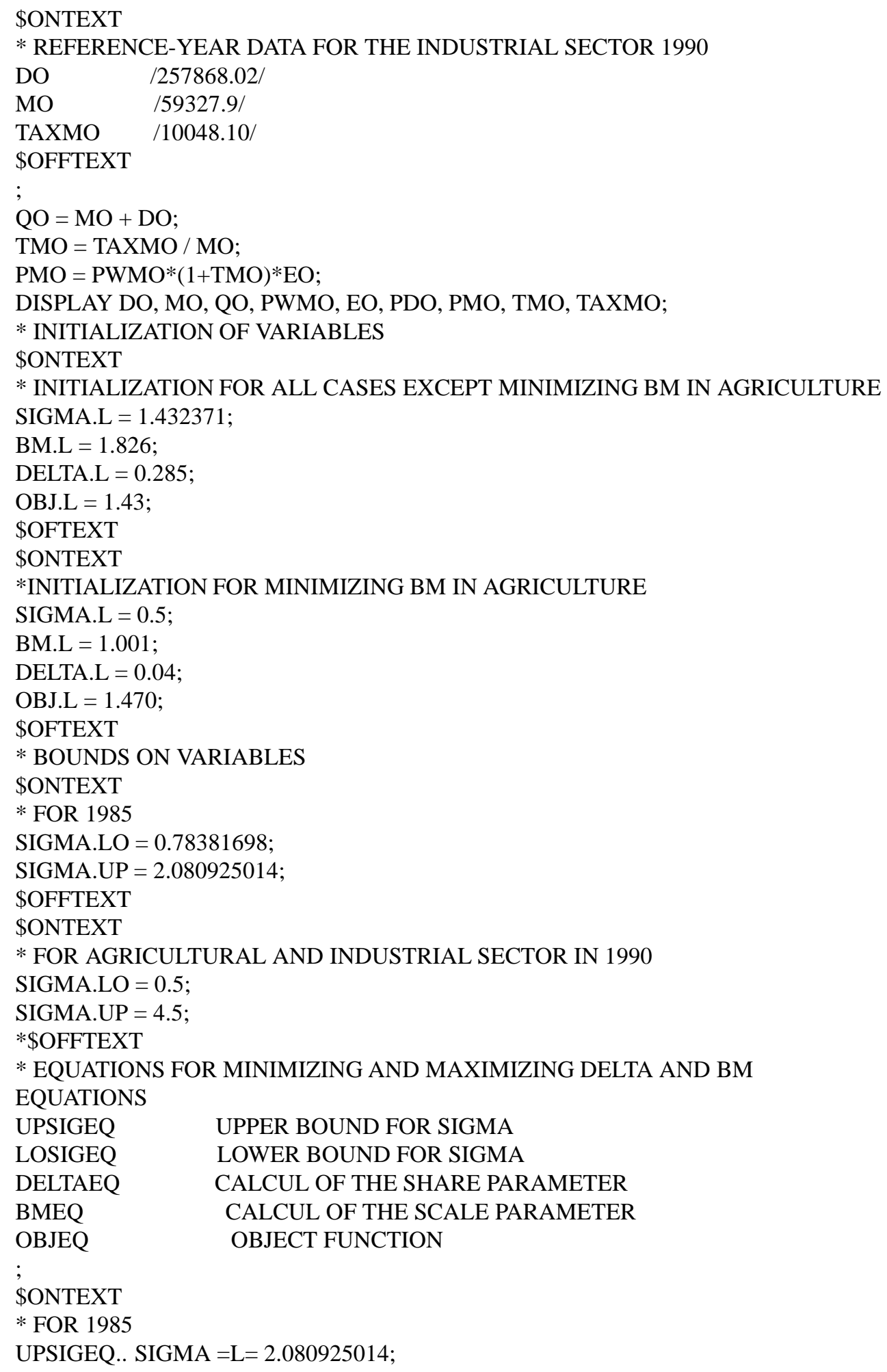


LOSIGEQ.. SIGMA $=\mathrm{G}=0.783816986$;

\$OFFTEXT

\$ONTEXT

* FOR AGRICULTURAL AND INDUSTRIAL SECTOR IN 1990

UPSIGEQ.. SIGMA $=\mathrm{L}=4.5$;

LOSIGEQ.. SIGMA $=\mathrm{G}=0.5$;

*\$OFFTEXT

BMEQ..

$\mathrm{QO}=\mathrm{E}=\mathrm{BM} *($ DELTA $*$ MO $* *(-((1-$ SIGMA $) /$ SIGMA $))+$ (1-DELTA $) *$ DO $* *(-((1-$ SIGMA $) /$ SIGMA $))) * *($ SIGMA/(SIGMA-1));

DELTAEQ..

OBJEQ.. $\mathrm{MO}=\mathrm{E}=(((\mathrm{DELTA} /(1-\mathrm{DELTA})) * *(\mathrm{SIGMA})) *((\mathrm{PDO} / \mathrm{PMO}) * * \mathrm{SIGMA})) * \mathrm{DO} ;$

OBJEQ.. $\mathrm{OBJ}=\mathrm{E}=\mathrm{DELTA}$;

OPTIONS LIMROW $=0$, LIMCOL $=0$

MODEL ARMIG /DELTAEQ, UPSIGEQ, LOSIGEQ, OBJEQ/;

MODEL ARMIG /DELTAEQ, BMEQ, UPSIGEQ, LOSIGEQ, OBJEQ/;

SOLVE ARMIG USING NLP MAXIMIZING OBJ;

SOLVE ARMIG USING NLP MINIMIZING OBJ;

DISPLAY SIGMA.L, DELTA.L;

DISPLAY SIGMA.L, DELTA.L, BM.L; 


\section{References}

ABDelkhaleK, T. (1994): "Inférence statistique pour modèles de simulation et modèles calculables d'équilibre général: théorie et applications à un modèle de l'économie marocaine," Ph.D. thesis, Département de sciences économiques, Université de Montréal.

AbdelkhaleK, T., And J.-M. Dufour (1998): "Statistical Inference for Computable General Equilibrium Models, with Application to a Model of the Moroccan Economy," Review of Economics and Statistics, LXXX, 520-534.

Abdelkhalek, T., And A. Martens (1996): "Macroclosures in Computable General Equilibrium Models : A Probabilistic Treatment with Application to Morocco," Discussion Paper 2596, Centre de recherche et développement en économique, Université de Montréal, Montreal.

Barnard, G. A. (1963): "Comment on "The Spectral Analysis of Point Processes" by M. S. Bartlett," Journal of the Royal Statistical Society, Series B, 25, 294.

Bernheim, D. B., J. K. Scholz, And J. B. Shoven (1989): “Consumption Taxation in a General Equilibrium Model: How Reliable are Simulation Results?," Discussion paper, Department of Economics, Stanford University, Stanford, California.

Brooke, A., D. Kendrick, And A. Meeraus (1988): GAMS: A User's Guide. The Scientific Press, Palo Alto, Redwood City, CA.

Byron, R. P. (1978): “The Estimation of Large Social Account Matrices," Journal of the Royal Statistical Society, Series A, General, 141, 359-367, Correction 142, 404.

DAW KINS, C. (1997): “Extended Sensitivity Analysis for Applied General Equilibrium Models,” Discussion paper, Department of Economics, Warwick University, U.K.

De Melo, J., And S. Robinson (1989): "Product Differentiation and General Equilibrium Models of Small Economies,” Journal of International Economics, 27, 47-67.

Decaluwé, B., And A. Martens (1988): "CGE Modeling and Developing Economies: A Concise Empirical Survey of 73 Applications to 26 Countries," Journal of Policy Modeling, 10, 529-568.

Devarajan, S., J. D. Lewis, And S. Robinson (1986): "A Bibliography of Computable General Equilibrium (CGE) Models Applied to Developing Countries,' Discussion Paper 224, Department of Economics, Harvard University, Cambridge, MA.

(1990): "Policy Lessons from Trade-Focused Two Sector Models," Journal of Policy Modeling, 12, $625-657$.

(1994): "Getting the Model Right: The General Equilibrium Approach to Adjustment Policy," Discussion paper, Department of Economics, Harvard University, Cambridge, MA.

DeVuyst, E., And P. V. Preckel (1997): "Sensitivity Analysis Revisited: A Quadrature-Based Approach,” Journal of Policy Modeling, 19, 175-185.

Dufour, J.-M. (1989): “Nonlinear Hypotheses, Inequality Restrictions, and Non-Nested Hypotheses: Exact Simultaneous Tests in Linear Regressions,” Econometrica, 57, 335-355.

(1990): "Exact Tests and Confidence Sets in Linear Regressions with Autocorrelated Errors," Econometrica, 58, 475-494. 
(1995): "Monte Carlo Tests with Nuisance Parameters: A General Approach to Finite-Sample Inference and Nonstandard Asymptotics in Econometrics," Discussion paper, C.R.D.E., Université de Montréal.

(1997): "Some Impossibility Theorems in Econometrics, with Applications to Structural and Dynamic Models," Econometrica, 65, 1365-1389.

DUFOUR, J.-M., AND J. JASIAK (1998): "Finite Sample Inference Methods for Simultaneous Equations and Models with Unobserved and Generated Regressors," Discussion paper, C.R.D.E., Université de Montréal, 30 pages.

Dufour, J.-M., AND J. F. Kiviet (1996): "Exact Tests for Structural Change in First-Order Dynamic Models," Journal of Econometrics, 70, 39-68.

(1998): "Exact Inference Methods for First-Order Autoregressive Distributed Lag Models," Econometrica, 66, 79-104.

Dwass, M. (1957): "Modified Randomization Tests for Nonparametric Hypotheses," Annals of Mathematical Statistics, 28, 181-187.

Gouriéroux, C., And A. Monfort (1989): Statistique et modèles économétriques, Volumes 1 et 2. Economica, Paris.

GROUPE DE RECHERCHE EN ÉCONOMIE INTERNATIONALE (G.R.E.I.) (1992): "La matrice de comptabilité sociale du Maroc de 1985," Discussion paper, Faculté des sciences juridiques, économiques et sociales, Centre d'études stratégiques, Université Mohammed V, Rabat.

Gunning, J. W., AND M. Keyzer (1995): “Applied General Equilibrium Models for Policy Analysis," in Handbook of Development Economics, ed. by J. Behrman, and T. N. Srinivasan, vol. 3A, pp. 2026-2107. North Holland, Amsterdam.

HARRISON, G. W. (1989): "The Sensitivity Analysis of Applied General Equilibrium Models: A Comparison of Methodologies," Discussion paper, Department of Economics, University of New Mexico.

Harrison, G. W., R. Jones, L. J. Kimbell, And R. Wigle (1993): "How Robust Is Applied General Equilibrium Analysis?," Journal of Policy Modeling, 15, 99-115.

HarRison, G. W., AND H. D. VinOD (1992): "The Sensitivity Analysis of Applied General Equilibrium Models: Completely Randomized Factorial Sampling Designs," Review of Economics and Statistics, 74, 357-362.

HARRISON, GlenN, W. (1986): "A General Equilibrium Analysis of Tarrif Reduction," in Srinivasan and Whalley (1986).

Jorgenson, D. W. (1984): "Econometric Methods for Applied General Equilibrium Analysis (with Comments)," in Scarf and Shoven (1984), pp. 139-205.

Kiviet, J., AND J.-M. Dufour (1997): "Exact Tests in Single Equation Autoregressive Distributed Lag Models," Journal of Econometrics, 80, 325-353.

Manne, A. S. (1985): "On the Formulation and Solution of Economic Equilibrium Models," Mathematical Programming Study, 23, 1-22.

MANSUR, A., AND J. Whalley (1984): "Numerical Specification of Applied General Equlibrium Models: Estimation, Calibration, and Data," in Scarf and Shoven (1984). 
MARTENS, A. (1993): "La politique économique de développement et les modèles calculables d'équilibre général: un mariage à la progéniture abondante," in Collection du G.R.E.I., Volume 1, ed. by D. Benali, and A. Martens, pp. 96-119. Université Mohamed V, Rabat, Morocco.

PAGAN, A. R., AND J. SHANNON (1985): "Sensitivity Analysis for Linearized Computable General Equilibrium Models," in New Developments in Applied General Equilibrium Analysis, ed. by J. Piggot, and J. Whalley. Cambridge University Press, Cambridge, U.K.

Pagan, Adrian, R., And J. Shannon (1989): "How Reliable are ORANI Conclusions?," Economic Record, 63, 33-45.

RAO, C. R. (1973): Linear Statistical Inference and its Applications. John Wiley \& Sons, New York, second edn.

REINERT, K., AND D. W. Roland-Holst (1992): “Armington Elasticities for United States Manufacturing Sectors," Journal of Policy Modeling, 15, 631-639.

SCARf, H. E., AND J. B. ShOven (eds.) (1984): Applied General Equilibrium Analysis. Cambridge University Press, Cambridge, U.K.

Shoven, J. B., AND J. Whalley (1984): "Applied General Equilibrium Models of Taxation and International Trade: an Introduction and Survey," Journal of Economic Literature, 22, 1007-1051.

(1992): Applying General Equilibrium. Cambridge University Press, Cambridge, U.K.

SRinivasan, T. N., And J. Whalley (eds.) (1986): General Equilibrium Trade Policy Modelling. The MIT Press, Cambridge, MA.

WigLe, R. (1986): "Summary of the Panel and Floor Discussion," in Srinivasan and Whalley (1986), pp. $323-354$.

(1991): "The Pagan-Shannon Approximation: Unconditional Systematic Sensitivity Analysis in Minutes," Empirical Economics, 16, 35-49. 


\section{Liste des publications au CIRANO *}

\section{Cahiers CIRANO / CIRANO Papers (ISSN 1198-8169)}

99c-1 Les Expos, l'OSM, les universités, les hôpitaux : Le coût d'un déficit de 400000 emplois au Québec — Expos, Montréal Symphony Orchestra, Universities, Hospitals: The Cost of a 400,000-Job Shortfall in Québec / Marcel Boyer

96c-1 Peut-on créer des emplois en réglementant le temps de travail? / Robert Lacroix

95c-2 Anomalies de marché et sélection des titres au Canada / Richard Guay, Jean-François L'Her et Jean-Marc Suret

95c-1 La réglementation incitative / Marcel Boyer

94c-3 L'importance relative des gouvernements: causes, conséquences et organisations alternative / Claude Montmarquette

94c-2 Commercial Bankruptcy and Financial Reorganization in Canada / Jocelyn Martel

94c-1 Faire ou faire faire : La perspective de l'économie des organisations / Michel Patry

Série Scientifique / Scientific Series (ISSN 1198-8177)

2000s-17 Markovian Processes, Two-Sided Autoregressions and Finite-Sample Inference for Stationary and Nonstationary Autoregressive Processes / Jean-Marie Dufour et Oliver Torrès

2000s-16 Exact Tests for Contemporaneous Correlation of Disturbances in Seemingly Unrelated Regressions / Jean-Marie Dufour et Lynda Khalaf

2000s-15 Simulation Based Finite and Large Sample Tests in Multivariate Regressions / Jean-Marie Dufour et Lynda Khalaf

2000s-14 Les obstacles à l'innovation dans les industries de services au Canada / Pierre Mohnen et Julio Rosa

2000s-13 Finite Sample Inference Methods for Simultaneous Equations and Models with Unobserved and Generated Regressors / Jean-Marie Dufour et Joanna Jasiak

2000s-12 Protection, Lobbying, and Market Structures / Arye Hillman, Ngo Van Long et Antoine Soubeyrand

2000s-11 The Asian Financial Crisis: The Role of Derivative Securities Trading and Foreign Investors / Eric Ghysels et Junghoon Seon

2000s-10 Productivity Trends and Employment across Industries in Canada / Pierre Mohnen et Thijs ten Raa

2000s-09 Nouvelle économie, nouvelle organisation et technologies de l'information / Suzanne Rivard

2000s-08 Semi-Stationary Equilibrium in Leader-Follower Games / Ngo Van Long et Koji Shimomura

* Vous pouvez consulter la liste complète des publications du CIRANO et les publications elles-mêmes sur notre site Internet à l'adresse suivante :

http://www.cirano.umontreal.ca/publication/documents.html 